\title{
Comparison between two Polyethersulfone concentrations in hollow fiber ultrafiltration membranes. Is it worth to use more polymer?
}

\author{
Karen Gonzaga $^{1+} \bullet$, Jose Carlos Mierzwa ${ }^{1} \bullet$ \\ 1.University of São Paulo, Engineering, Polytechnic School, Department of Hydraulic and Environmental, São Paulo, \\ São Paulo, Brazil.
}

+Corresponding author: Karen Gonzaga, Phone: +55 11 3039-3273, Email address: karen.gonzaga@email.com

\section{ARTICLE INFO}

Article history:

Received: January 23, 2020

Accepted: July 11, 2020

Published: January 01, 2021

\section{Keywords}

1. polyethersulfone

2. hollow fiber

3. membranes

4. phase inversion

\begin{abstract}
Polyethersulfone (PES) hollow fiber membranes were fabricated using dry-jet wet spinning technique, a phase inversion method, with 16 and $20 \%$ PES, N-methyl-2-pyrrolidone (NMP) as solvent and tap water as nonsolvent, in order to evaluate if the amount of polymer has a significant effect on its properties. They were characterized using SEM for a morphological analysis, a continuous system to measure pure water permeability (PWP) and molecular weight cutoff (MWCO), and a universal testing machine to tensile tests. The obtained results for PWP was an average of about $220 \mathrm{~L} \mathrm{~m}^{-2} \mathrm{~h}^{-1}$ bar $^{-1}$ for the $16 \%$ PES membrane and $174 \mathrm{~L} \mathrm{~m}^{-2} \mathrm{~h}^{-1}$ bar $^{-1}$ for the $20 \% \mathrm{PES}$ membrane. The results of mechanical resistance and MWCO did not present statistical differences. Thus, it is confirmed that the $16 \%$ PES membrane can be as good as the $20 \%$, despite using less polymer, a finding that can further motivate membrane modification studies and other related works.
\end{abstract}

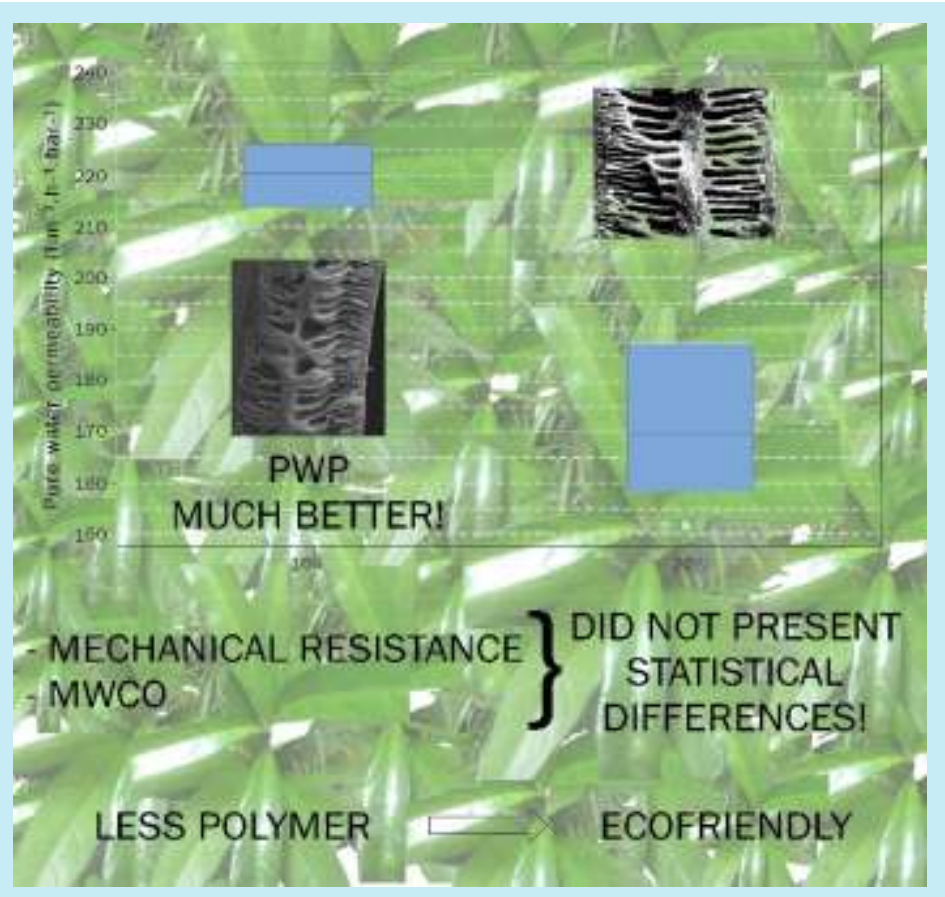




\section{Introduction}

Polymeric hollow fiber membranes were first developed by Dow Chemical in 1966 and since then, due to their properties as high processability and low cost, they are the most common material used for membrane fabrication ${ }^{1-3}$. Hollow fiber membranes are used in several areas that demand a separation process, such as pharmaceutical industry, food industry, water and wastewater treatment plants and the petroleum sector $^{4,5}$.

The method of phase inversion is one of the most important techniques of membrane fabrication ${ }^{6}$ for hollow fibers. It is based on an extrusion of a polymer solution through a spinneret, which will return to the solid state ${ }^{6,7}$. Dry-jet wet spinning follows this idea with a phase inversion beginning with an induced evaporation that occurs in the air gap and finishing in the coagulation bath with a phase inversion induced by diffusion ${ }^{1}$.

Polyethersulfone (PES) has been widely used because it can tolerate a large range of $\mathrm{pH}$, has a good thermal stability and excellent chemical and mechanical resistance ${ }^{6,8,9}$. This polymer and the conditions for the solution spinning determine the morphology and properties of hollow fiber membrane, such as selectivity ${ }^{7,10}$.

Despite numerous studies related to hollow fiber membranes composed of PES ${ }^{11-16}$ and the known advantages of membrane separation processes ${ }^{17-19}$, there is a worldwide concern with the amount of microplastics that are emerging around the globe ${ }^{20-23}$ and not only with energy efficiency, pollutant emissions and other sustainability issues. Lower consumption of plastic is a policy growing in many countries, seeking to encourage consumers to find a way to reduce it on a daily basis ${ }^{24}$.

Based on this tendency, the present work focuses on studying the properties of hollow fiber membranes made of 16 and 20\% PES, evaluating if there are significant differences among the results obtained that justify the use of a bigger quantity of polymer. Future studies of membrane modification can be based on compositions using smaller amounts of polymer without impairing its application, demonstrating its importance.

\section{Experimental}

\subsection{Materials}

Polyethersulfone (VERADEL 3000P with MW = 63,000 g Mol-1) from Solvay Advanced Polymer was dried for $4 \mathrm{~h}$ in an oven at $100{ }^{\circ} \mathrm{C}$ before utilizing it for fabrication of the dope solution. N-methyl-2pyrrolidone (NMP) with purity $>99 \%$ from Labsynth Produtos para Laboratórios Ltda. was used as received as the solvent for the polymer. Tap water was used as the nonsolvent agent, as bore fluid and in coagulation bath.

\subsection{Solution preparation}

The dope solution was prepared with 16 and $20 \%$ (weight/weight) concentration of PES, with the remaining concentration (84 and $80 \%$, respectively) being of NMP. The polymer was slowly added to the solvent, taking $1 \mathrm{~h}$ for complete addition, at room temperature. Then, the solution remained for about 18 $\mathrm{h}$ at 200 r.p.m. stirring, assuring complete solubilization of the polymer and homogenization, to be finally degassed in an ultrasonic bath for $1 \mathrm{~h}$, eliminating any bubbles of air trapped into solution.

\subsection{Hollow fiber production}

The solution was spinning with a solution flow rate of $2 \mathrm{~mL} \mathrm{~min}^{-1}$ and a bore fluid flow rate of $4 \mathrm{~mL} \mathrm{~min} \mathrm{~m}^{-1}$, using dry-jet wet spinning method with an air gap of $2 \mathrm{~cm}$ and take-up speed of $4 \mathrm{~mL} \mathrm{~min}^{-1}$, at room temperature. A schematic representation of the spinneret and fabricating hollow fiber membrane processes is shown in Fig. 1.

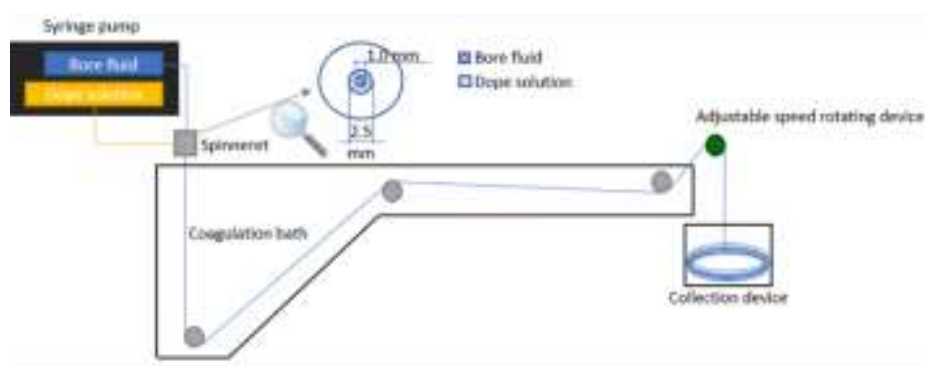

Figure 1. Schematic representation of fabricating hollow fiber membrane system.

Hollow fiber membranes were stored in demineralized water to keep their integrity. To realize some characterization procedures, these were dried following the steps described elsewhere ${ }^{25}$.

\subsection{Membrane characterization}

The produced membranes were investigated about its morphology, permeability, mechanical resistance and MWCO (molecular weight cutoff). The data 
obtained were treated to remove outliers and statistical analysis of the results was done using Minitab ${ }^{\circledR}$ 18.1, from Minitab, Inc., assuming a significance level of 0.05 and equality of variances.

\subsubsection{Morphological analysis}

The cross-sectional of the hollow fiber membranes was observed by a scanning electron microscope (Zeiss SEM model EVO MA10) with an acceleration voltage of $20 \mathrm{kV}$. For this, dried membranes were cut under liquid nitrogen and sputter-coated with a thin film of gold-platinum. These procedures under nitrogen are necessary to produce a clean and brittle fracture and the coating is required due to the nature of polymeric material, not electrically conductive. Doing this way, it is possible to see the microstructure of the produced membranes.

\subsubsection{Pure water permeability}

Pure water permeability (PWP) measurements were estimated in an experimental setup, where a module made from low-density polyethylene (LDPE) was utilized with two hollow fiber membranes with $30 \mathrm{~cm}$ effective lengths, folded in half and fed topside in an inside out mode.

A syringe pump with a constant flow rate of $0.5 \mathrm{~mL}$ $\min ^{-1}$ supplied demineralized water to the module and the water production measurement was started after thirty minutes to achieve steady-state conditions. Records were made every five minutes for one hour, similar to the procedure previously described ${ }^{26}$. The permeation flux $\left(\mathrm{J}_{\mathrm{w}}\right)$ through the membrane was calculated following the Eq. 1:

$J_{w}=\frac{V}{A * t * \Delta P}$

where: $J_{\mathrm{w}}=$ Water permeability $\left(\mathrm{L} \mathrm{m}^{-2} \mathrm{~h}^{-1} \mathrm{bar}^{-1}\right) ; \mathrm{V}=$ Volume of permeate $(\mathrm{L}) ; \mathrm{A}=$ Inner surface area $\left(\mathrm{m}^{-2}\right) ; \mathrm{t}$ $=$ Time $(\mathrm{h}) ; \Delta \mathrm{P}=$ Transmembrane pressure (bar).

\subsubsection{Mechanical resistance}

The mechanical resistance of the hollow fiber membranes was investigated by means of tensile tests, measured using an Instron universal testing system and a $100 \mathrm{~N}$ load cell and constant rate of $1 \mathrm{~mm} \mathrm{~s}^{-1}$, with an initial gauge length of $30 \mathrm{~mm}$. The test method was based on ASTM 1557-14 Standard Test Method for Tensile Strength and Young's Modulus of Fibers.
Five dried samples with $100 \mathrm{~mm}$ length were tested for each experimental result, determining membrane tensile strength, elongation at break and Young's modulus.

\subsubsection{Molecular weight cutoff (MWCO)}

The MWCO was investigated using 200 ppm polyethylene glycol (PEG) solution with molecular weights of $10 \mathrm{kDa}, 32 \mathrm{kDa}, 90 \mathrm{kDa}$ and $150 \mathrm{kDa}$, into the same system and module described in 2.4.2.

The concentration of PEG in permeate and in retentate was analyzed by a UV-VIS spectrophotometer (WUV-M51, Weblaborsp) at a wavelength of $254 \mathrm{~nm}$ and the MWCO was determined from the rejection of PEG solution, following Eq. 2:

$R=\left(1-\frac{c_{p}}{C_{r}}\right) * 100 \%$

where: $\mathrm{R}=$ Rejection (\%); $\mathrm{C}_{\mathrm{p}}=$ Permeate concentration $(\mathrm{Da}) ; \mathrm{C}_{\mathrm{r}}=$ Retentate concentration $(\mathrm{Da})$.

\section{Results and discussion}

\subsection{Morphological analysis}

To evaluate the impact of polymer concentration on the morphology of hollow fiber membranes, SEM was used to observe its enlarged cross section and outside face of the samples. Figures 2 and 3 show both membranes resulted in an outside dense skin and a double layered finger-like structure pore, but it is possible to see that the $16 \%$ PES concentration membrane has a bigger aperture at the end of the pores, nearby their center.

Double layer finger-like and dense skin were expected microstructure characteristics for these membranes. They occur because water is a strong nonsolvent for the polymer, that provides a fast coagulation, and this formation is a consequence of it, like reported previously ${ }^{11,27,28}$.

The morphological analysis indicates that the permeation flux tends to be better in the 16\% PES concentration membrane. This tendency is verified by pure water permeability investigation results, but it can happen because its pores had an opening larger than the other membrane, facilitating the flow of the fluid through it. 


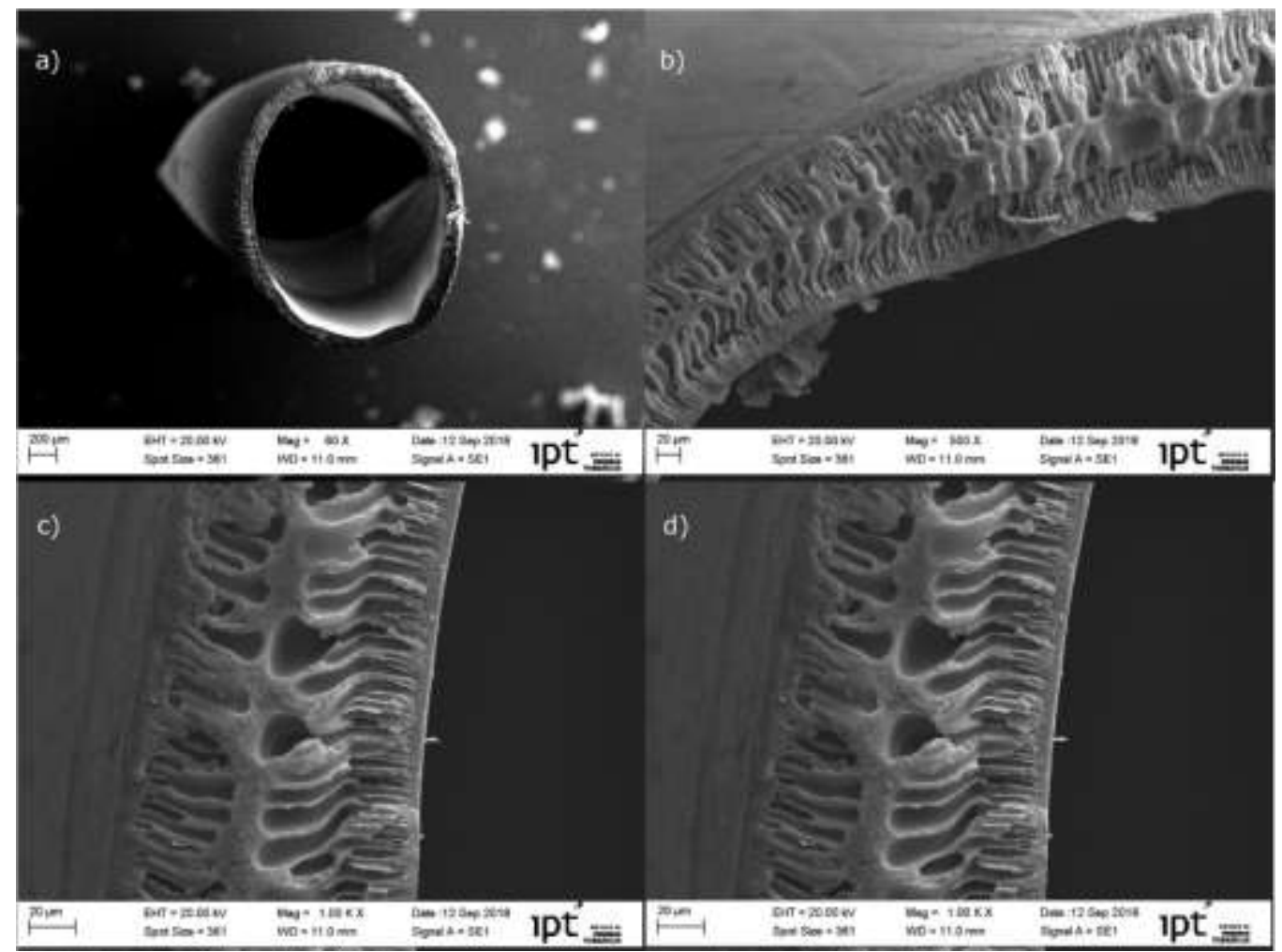

Figure 2. SEM images of 16\% PES sample: a) full cross section of the hollow fiber membrane, b) and c) cross section of the hollow fiber membrane with different magnifications, and d) outer skin.

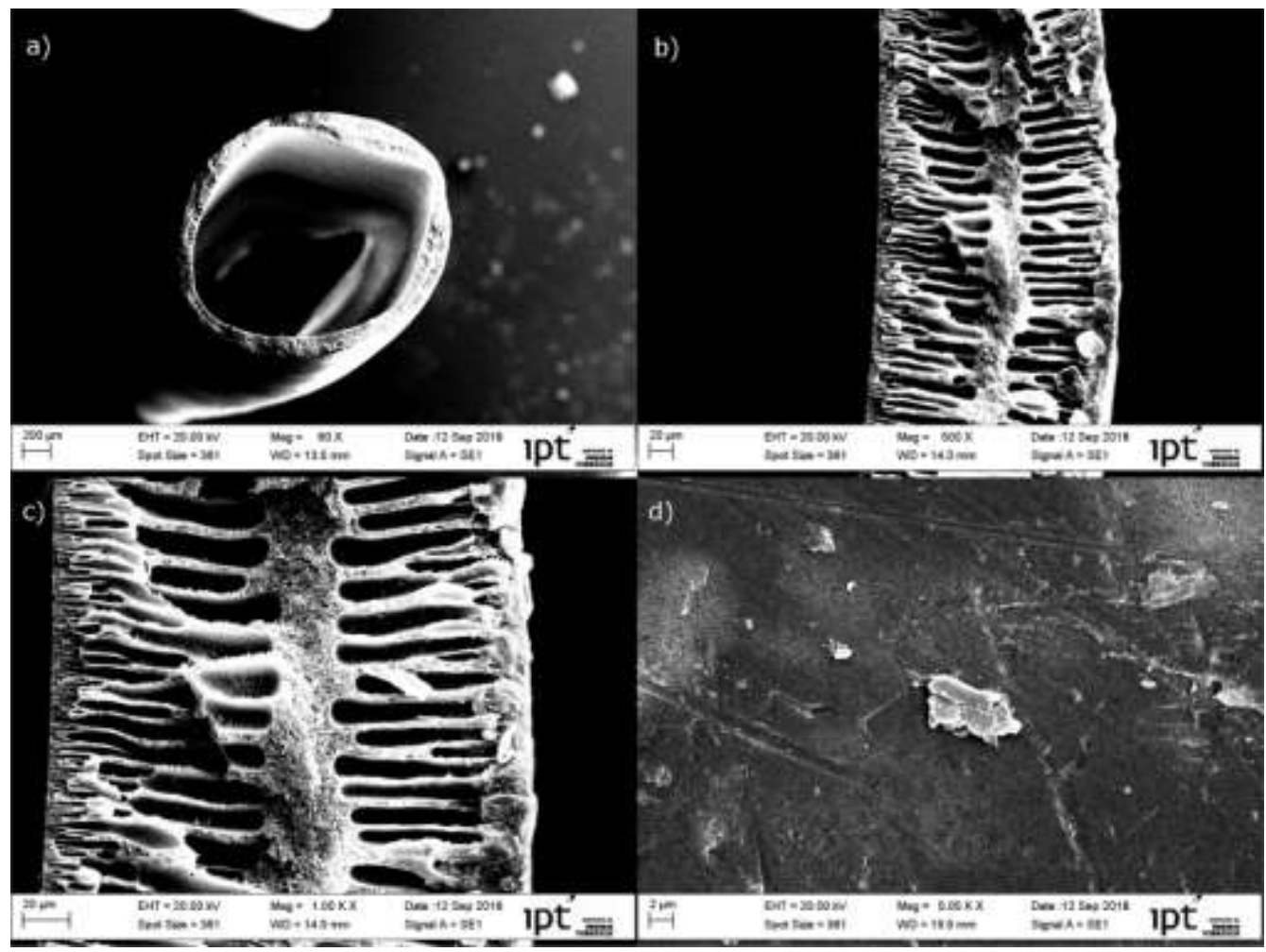

Figure 3. SEM images of $20 \%$ PES sample: a) full cross section of the hollow fiber membrane, b) and c) cross section of the hollow fiber membrane with different magnifications, and d) outer skin. 


\subsection{Pure water permeability}

The results of demineralized water permeation flux for the hollow fiber membranes produced are shown in Fig. 4. It shows an average permeability about $220 \mathrm{~L}$ $\mathrm{m}^{-2} \mathrm{~h}^{-1}$ bar-1 $^{-1}$ for the $16 \%$ PES concentration membrane and $174 \mathrm{~L} \mathrm{~m}^{-2} \mathrm{~h}^{-1} \mathrm{bar}^{-1}$ for the $20 \%$ PES concentration membrane. These results agree with the SEM analysis showed above and also with reports in the literature ${ }^{29,30}$.

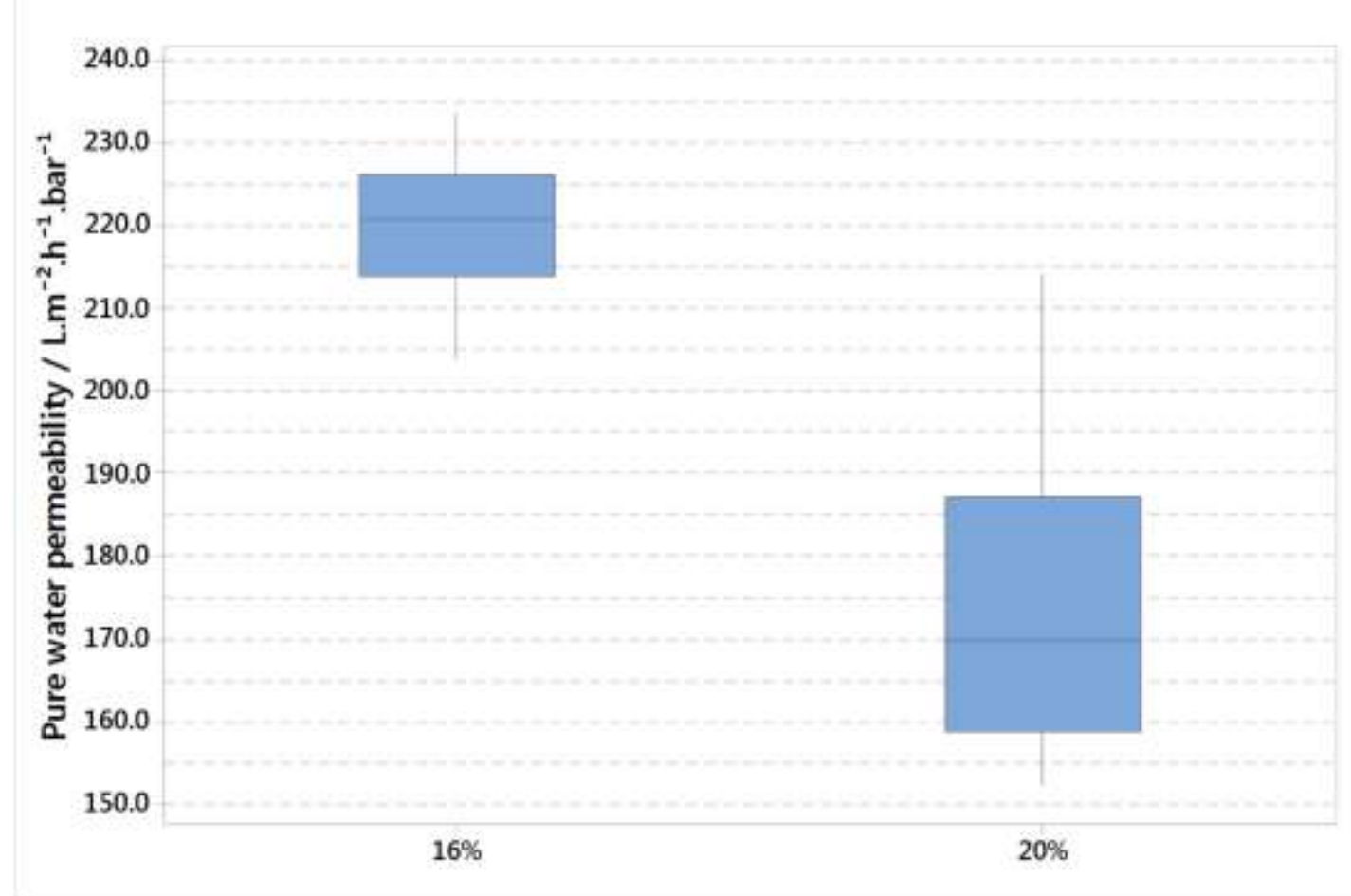

Figure 4. Pure water permeability of 16\% PES and 20\% PES membranes.

Table 1 shows statistical analysis of the results of permeability presented. According to ANOVA evaluation, there is a statistical difference between them.

Table 1. ANOVA statistical analysis of membranes PWP.

\begin{tabular}{|l|c|c|c|c|c|}
\hline Source & DF & Adj. SS & Adj. MS & F-Value & P-Value \\
\hline Factor & 1 & 12208 & 12207.90 & 56.11 & 0.000 \\
\hline Error & 22 & 4787 & 217.60 & & \\
\hline Total & 23 & 16995 & & & \\
\hline
\end{tabular}

\subsection{Mechanical resistance}

The results of the mechanical properties investigation for membranes are summarized in Tab. 2.

Table 2. Mechanical resistance properties of membranes.

\begin{tabular}{|l|c|c|c|c|c|c|}
\hline Sample & \multicolumn{2}{|c|}{ Tensile strength / MPa } & \multicolumn{2}{c|}{ Elongation at break / \% } & \multicolumn{2}{c|}{ Young's Modulus / MPa } \\
\cline { 2 - 7 } & Average & Standard deviation & Average & Standard deviation & Average & Standard deviation \\
\hline $16 \%$ & 220 & 9 & 15 & 2 & 180 & 47 \\
\hline $20 \%$ & 174 & 19 & 15 & 2 & 279 & 54 \\
\hline
\end{tabular}


These results show there is a small variance between the average of tensile strength, elongation at break and Young's modulus. With the analysis of results, it is possible to note there is no relevant difference between the 16 and 20\% PES membranes (Tabs. 3 to 5).

Table 3. ANOVA statistical analysis of membranes tensile strength.

\begin{tabular}{|l|c|c|c|c|c|}
\hline Source & DF & Adj. SS & Adj. MS & F-Value & P-Value \\
\hline Factor & 1 & 0.0918 & 0.09177 & 0.02 & 0.884 \\
\hline Error & 7 & 28.0531 & 4.00759 & & \\
\hline Total & 8 & 28.1449 & & & \\
\hline
\end{tabular}

Table 4. ANOVA statistical analysis of membranes elongation at break.

\begin{tabular}{|l|c|c|c|c|c|}
\hline Source & DF & Adj. SS & Adj. MS & F-Value & P-Value \\
\hline Factor & 1 & 167.6 & 167.6 & 1.18 & 0.339 \\
\hline Error & 4 & 568.8 & 142.2 & & \\
\hline Total & 5 & 736.4 & & & \\
\hline
\end{tabular}

Table 5. ANOVA statistical analysis of membranes Young's Modulus.

\begin{tabular}{|l|c|c|c|c|c|}
\hline Source & DF & Adj. SS & Adj. MS & F-Value & P-Value \\
\hline Factor & 1 & 14656 & 14656 & 5.73 & 0.075 \\
\hline Error & 4 & 10235 & 2559 & & \\
\hline Total & 5 & 24891 & & & \\
\hline
\end{tabular}

\subsection{MWCO}

The data obtained for MWCO were recorded up to PEG $150 \mathrm{kDa}$ MW and the membranes were not able to remove $90 \%$ of this substance, which is the concept of MWCO. Thus, to estimate this important characteristic of membranes and knowing that the typical rejection curve is sigmoidal $^{31,32}$, an extrapolation was made with the results (Fig. 5 and 6).

Based on the point that represents $90 \%$ of removal in these curves, values of $271 \mathrm{kDa}$ and $279 \mathrm{kDa}$ are the MWCO estimated of $16 \%$ PES membrane and $20 \%$ PES membrane, respectively. The statistical analysis does not show a relevant difference between both results, as demonstrated in Tab. 6.

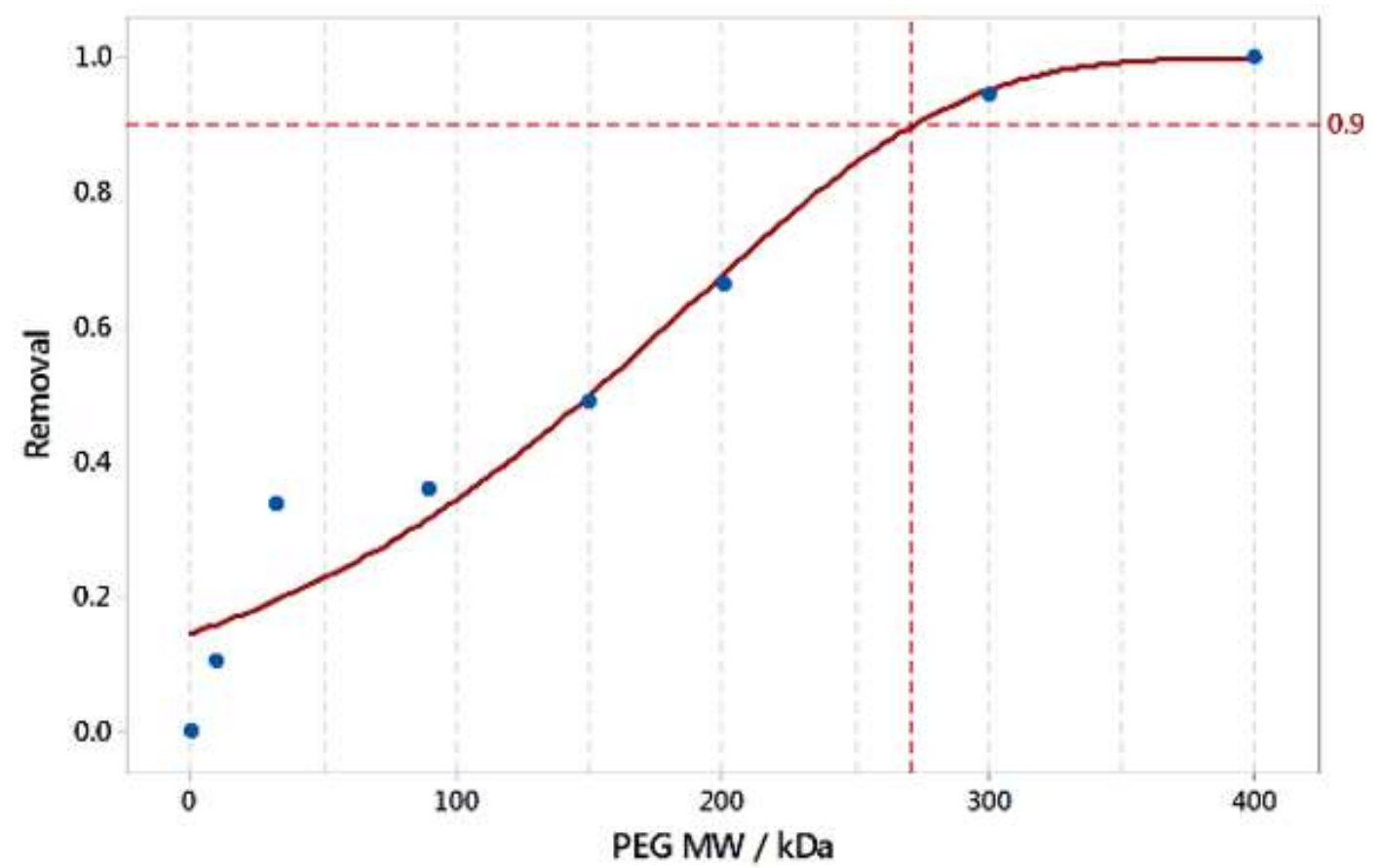

Figure 5. 16\% PES membrane MWCO. 


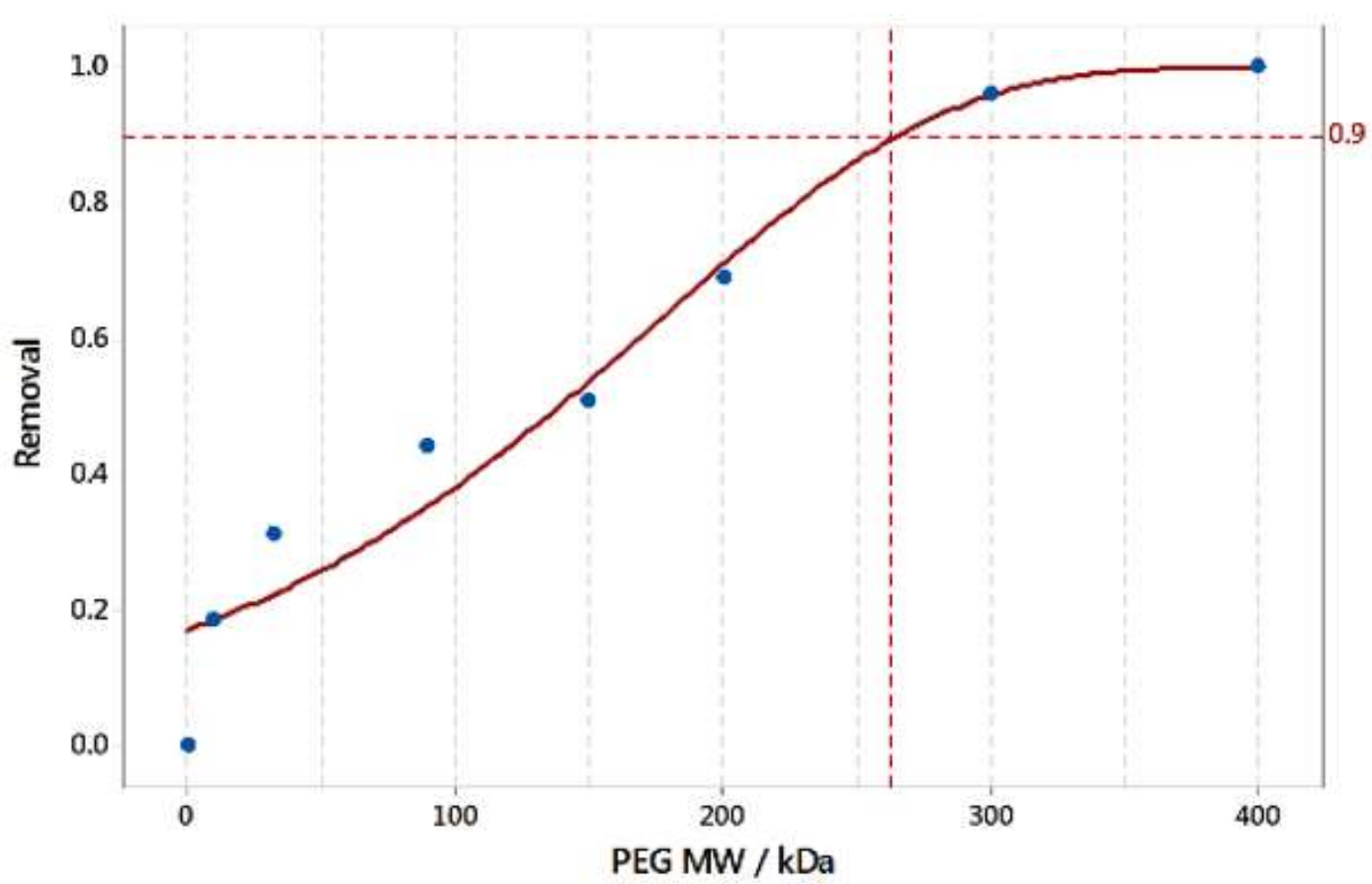

Figure 6. 20\% PES membrane MWCO.

Table 6. ANOVA statistical analysis of membranes MWCO.

\begin{tabular}{|l|l|l|l|l|l|}
\hline Source & DF & Adj. SS & Adj. MS & F-Value & P-Value \\
\hline Factor & 1 & 0.00238 & 0.002377 & 0.02 & 0.894 \\
\hline Error & 14 & 1.81083 & 0.129345 & & \\
\hline Total & 15 & 1.81320 & & & \\
\hline
\end{tabular}

\section{Conclusions}

In this work, 16 and 20\% PES membranes were compared to verify whether the concentration of polymer can determine a significant difference between them. Based on results obtained, it is possible to observe that the only relevant statistical difference was PWP, which is almost 25\% better in the $16 \%$ PES membrane, implying a minor energy consumption to produce the same volume of permeate compared to the 20\% PES. All other results have no relevant statistical difference among the compared membranes.

Future studies involving membrane modification can benefit from this research and motivate researchers to develop other works with related themes.

\section{Acknowledgments}

The authors thank the Institute for Technological Research of the State of São Paulo (IPT) for supporting and providing SEM images on this research.

\section{References}

[1] Bildyukevich, A. V., Plisko, T. V. Usosky, V. V., The formation of polysulfone hollow fiber membranes by the free fall spinning method, Petroleum Chemistry 56 (2) (2016)

$379-400$ https://doi.org/10.1134/S0965544116050042.

[2] Kurada, K. V., De, S., Modeling of solution thermodynamics: A method for tuning the properties of blend polymeric membranes, Journal of Membrane Science 540 (2017) 485-495 https://doi.org/10.1016/j.memsci.2017.06.049.

[3] Werber, J. R., Osuji, C. O., Elimelech, M., Materials for next-generation desalination and water purification membranes, Nature Reviews Materials 1 (2016) 16018. https://doi.org/10.1038/natrevmats.2016.18.

[4] Khulbe, K. C., Matsuura, T., Recent progress in polymeric hollow-fibre membrane preparation and applications, Membrane Technology 2016 (7) (2016) 7-13. https://doi.org/10.1016/S0958-2118(16)30149-5.

[5] Simone, S., Galiano, F., Faccini, M., Boerrigter, M. E., Chaumette, C., Drioli, E., Figoli, A., Preparation and 
Characterization of Polymeric-Hybrid $\mathrm{PES} / \mathrm{TiO}_{2}$ Hollow Fiber Membranes for Potential Applications in Water $\begin{array}{llllll}\text { Treatment, } & \text { Fibers } & 5 & \text { (2) } & \text { (2017) }\end{array}$ https://doi.org/10.3390/fib5020014.

[6] Lan, P., Wang, W., Structure Morphology of Polyethersulfone Hollow Fiber Membrane via Immersion Precipitation Phase Inversion Process, Applied Mechanics and Materials 152-154 (2012) 574-578. https://doi.org/10.4028/www.scientific.net/AMM.152154.574 .

[7] Ahmad, A. L., Otitoju, T. A., Ooi, B. S., Hollow fiber (HF) membrane fabrication: A review on the effects of solution spinning conditions on morphology and performance, Journal of Industrial and Engineering $\begin{array}{llll}\text { Chemistry } & 70 & \text { (2019) } & \text { 35-50. }\end{array}$ https://doi.org/10.1016/j.jiec.2018.10.005.

[8] Chew, C. M., Aroua, M. K., Hussain, M. A., Advanced process control for ultrafiltration membrane water treatment system, Journal of Cleaner Production 179 (2018) 63-80. https://doi.org/10.1016/j.jclepro.2018.01.075.

[9] Tsehaye, M. T., Velizarov, S., Van der Bruggen, B., Stability of polyethersulfone membranes to oxidative agents: A review, Polymer Degradation and Stability 157 (2018) 1553. https://doi.org/10.1016/j.polymdegradstab.2018.09.004.

[10] Alsalhy, Q. F., Salih, H. A., Simone, S., Zablouk, M., Drioli, E., Figoli, A., Poly(ether sulfone) (PES) hollow-fiber membranes prepared from various spinning parameters, Desalination $345 \quad$ (2014) 21-35. https://doi.org/10.1016/j.desal.2014.04.029.

[11] Xu, Z.-L., Qusay, F. A., Polyethersulfone (PES) hollow fiber ultrafiltration membranes prepared by PES/nonsolvent/NMP solution, Journal of Membrane Science 233 (12) (2004)

https://doi.org/10.1016/j.memsci.2004.01.005.

[12] Liu, T., Xu, S., Zhang, D., Sourirajan, S., Matsuura, T., Pore size and pore size distribution on the surface of polyethersulfone hollow fiber membranes, Desalination 85 (1) (1991) 1-12. https://doi.org/10.1016/00119164(91)85142-H.

[13] Chung, T. S., Hu, X., Effect of air-gap distance on the morphology and thermal properties of polyethersulfone hollow fibers, Journal of Applied Polymer Science 66 (6) (1997) 1067-1077. https://doi.org/10.1002/(SICI)10974628(19971107)66:6\%3C1067::AID-APP7\%3E3.0.CO;2-G.

[14] Thong, Z., Gao, J., Zoe, J. X., Wang, K.-Y., Chung, T.S., Fabrication of loose outer-selective nanofiltration (NF) polyethersulfone (PES) hollow fibers via single-step spinning process for dye removal, Separation and $\begin{array}{lllll}\text { Purification Technology } & 192 & \text { (2018) 483-490. }\end{array}$ https://doi.org/10.1016/j.seppur.2017.10.031.
[15] Xu, Z.-L., Qusay, F. A., Effect of Polyethylene Glycol Molecular Weights and Concentrations on Polyethersulfone Hollow Fiber Ultrafiltration Membranes, Journal of Applied Polymer Science $91 \quad$ (5) (2004) 3398-3407. https://doi.org/10.1002/app.13580.

[16] Chung, T. S., Teoh, S. K., Hu, X., Formation of ultrathin high-performance polyethersulfone hollow-fiber membranes, Journal of Membrane Science 133 (2) (1997) 161-175. https://doi.org/10.1016/S0376-7388(97)00101-4.

[17] Deng, K., Liu, Z., Luo, F., Xie, R., He, X.-H., Jiang, M.-Y., Ju, X.J., Wang, W., Chu, L.-Y., Controllable fabrication of polyethersulfone hollow fiber membranes with a facile double co-axial microfluidic device, Journal of Membrane Science $526 \quad$ (2017) 9-17. https://doi.org/10.1016/j.memsci.2016.12.012.

[18] Prisciandaro, M., Di Celso, G. M., On the removal of natural organic matter from superficial water by using UF and MF membranes, Desalination and Water Treatment 57 (6) (2016) 2481-2488. https://doi.org/10.1080/19443994.2015.1031184.

[19] Le, N. L., Nunes, S. P., Materials and membrane technologies for water and energy sustainability, Sustainable Materials and Technologies 7 (2016) 1-28. https://doi.org/10.1016/j.susmat.2016.02.001.

[20] Novotna, K., Cermakova, L., Pivokonska, L., Cajthaml, T., Pivokonky, M., Microplastics in drinking water treatment - Current knowledge and research needs, Science of the $\begin{array}{llll}\text { Total Environment } & 667 & \text { (2019) 730-740. }\end{array}$ https://doi.org/10.1016/j.scitotenv.2019.02.431.

[21] Wang, Z., Lin, T., Chen, W., Occurrence and removal of microplastics in an advanced drinking water treatment plant (ADWTP), Science of the Total Environment 700 (2020) 134520 . https://doi.org/10.1016/j.scitotenv.2019.134520.

[22] Ma, B., Xu, W., Hu, C., Liu, H., Qu, J., Li, L., Characteristics of microplastic removal via coagulation and ultrafiltration during drinking water treatment, Chemical $\begin{array}{llll}\text { Engineering Journal } & 359 & \text { (2019) 159-167. }\end{array}$ https://doi.org/10.1016/j.cej.2018.11.155.

[23] Koelmans, A. A., Nor, N. H. M., Hermsen, E., Kooi, M., Mintenig, S. M., De France, J., Microplastics in freshwaters and drinking water: Critical review and assessment of data quality, Water Research 155 (2019) 410422. https://doi.org/10.1016/j.watres.2019.02.054.

[24] Septianto, F., Lee, M. S. W., Emotional responses to plastic waste: Matching image and message framing in encouraging consumers to reduce plastic consumption, Australasian Marketing Journal 28 (1) (2020) 18-29. https://doi.org/10.1016/j.ausmj.2019.09.002. 
[25] Morihama, A. C. D., Mierzwa, J. C., Clay nanoparticles effects on performance and morphology of poly(vinylidene fluoride) membranes, Brazilian Journal of Chemical $\begin{array}{lllll}\text { Engineering } & 31 & \text { (1) } & \text { (2014) }\end{array}$ https://doi.org/10.1590/S0104-66322014000100009.

[26] Arahman, N., Mulyati, S., Lubis, M. R., Razi, F., Takagi, R., Matsuyama, H., Modification of polyethersulfone hollow fiber membrane with different polymeric additives, Membrane Water Treatment 7 (4) (2016) 355-365. https://doi.org/10.12989/mwt.2016.7.4.355.

[27] Qin, J.-J., Gu, J., Chung, T.-S., Effect of wet and dry-jet wet spinning on the shear-induced orientation during the formation of ultrafiltration hollow fiber membranes, Journal of Membrane Science 182 (1-2) (2001) 57-75. https://doi.org/10.1016/S0376-7388(00)00552-4.

[28] Wan, P., Yin, J., Deng, B., Seven-bore hollow fiber membrane (HFM) for ultrafiltration (UF), Chemical Engineering Research and Design 128 (2017) 240-247. https://doi.org/10.1016/j.cherd.2017.09.019.

[29] Al Aani, S., Wright, C. J., Hilal, N., Investigation of UF membranes fouling and potentials as pre-treatment step in desalination and surface water applications, Desalination 432 (2018) 115-127. https://doi.org/10.1016/j.desal.2018.01.017.

[30] Lalia, B. S., Kochkodan, V., Hashaikeh, R., Hilal, N., A review on membrane fabrication: Structure, properties and performance relationship, Desalination 326 (2013) 77-95. https://doi.org/10.1016/j.desal.2013.06.016.

[31] Van der Bruggen, B., Mänttäri, M., Nyström, M., Drawbacks of applying nanofiltration and how to avoid them: A review, Separation and Purification Technology 63 (2) (2008) 251-263. https://doi.org/10.1016/j.seppur.2008.05.010.

[32] Rodrigues, R., Morihama, A. C. D., Barbosa, I. M., Leocádio, G. N., Mierzwa, J. C., Clay Nanoparticles Composite Membranes Prepared with Three Different Polymers: Performance Evaluation, Journal of Membrane and Separation Technology 7 (2018) 1-11. https://doi.org/10.6000/1929-6037.2018.07.01. 